\title{
Modelling molecular iodine emissions in a coastal marine environment: the link to new particle formation
}

\author{
A. Saiz-Lopez ${ }^{1}$, J. M. C. Plane ${ }^{1}$, G. McFiggans ${ }^{2}$, P. I. Williams ${ }^{2}$, S. M. Ball ${ }^{3}$, M. Bitter ${ }^{3}$, R. L. Jones ${ }^{3}$, C. Hongwei ${ }^{4}$, \\ and T. Hoffmann ${ }^{4}$ \\ ${ }^{1}$ School of Environmental Sciences, University of East Anglia, Norwich, UK \\ ${ }^{2}$ School of Earth, Atmospheric \& Environmental Sciences, University of Manchester, Manchester, UK \\ ${ }^{3}$ University Chemical Laboratory, Cambridge University, Cambridge, UK \\ ${ }^{4}$ Institute of Inorganic Chemistry and Analytical Chemistry, Johannes Gutenberg-University, Mainz, Germany
}

Received: 27 May 2005 - Published in Atmos. Chem. Phys. Discuss.: 28 July 2005

Revised: 12 January 2006 - Accepted: 26 January 2006 - Published: 20 March 2006

\begin{abstract}
A model of iodine chemistry in the marine boundary layer (MBL) has been used to investigate the impact of daytime coastal emissions of molecular iodine $\left(\mathrm{I}_{2}\right)$. The model contains a full treatment of gas-phase iodine chemistry, combined with a description of the nucleation and growth, by condensation and coagulation, of iodine oxide nano-particles. In-situ measurements of coastal emissions of $\mathrm{I}_{2}$ made by the broadband cavity ring-down spectroscopy (BBCRDS) and inductively coupled plasmamass spectrometry (ICP/MS) techniques are presented and compared to long path differential optical absorption spectroscopy (DOAS) observations of $\mathrm{I}_{2}$ at Mace Head, Ireland. Simultaneous measurements of enhanced $\mathrm{I}_{2}$ emissions and particle bursts show that $I_{2}$ is almost certainly the main precursor of new particles at this coastal location. The ratio of $\mathrm{IO}$ to $\mathrm{I}_{2}$ predicted by the model indicates that the iodine species observed by the DOAS are concentrated over a short distance (about $8 \%$ of the $4.2 \mathrm{~km}$ light path) consistent with the intertidal zone, bringing them into good agreement with the $\mathrm{I}_{2}$ measurements made by the two in-situ techniques. The model is then used to investigate the effect of iodine emission on ozone depletion, and the production of new particles and their evolution to form stable cloud condensation nuclei $(\mathrm{CCN})$.
\end{abstract}

\section{Introduction}

The relevance of iodine in the chemistry of the lower troposphere has been the subject of numerous studies over the past two decades (Chameides and Davis, 1980; Jenkin et al.,

Correspondence to: J. M. C. Plane

(j.plane@uea.ac.uk)
1985; Davis et al., 1996; Vogt et al., 1999; McFiggans et al., 2000; Carpenter, 2003). These investigations have concentrated on the potential of iodine to affect the oxidising capacity of the MBL in a number of ways: catalytic destruction of $\mathrm{O}_{3}$ by cycles involving the iodine species IO, HOI and OIO; altering the partitioning of $\mathrm{NO}_{\mathrm{x}}\left(\mathrm{NO}_{2} / \mathrm{NO}\right)$ and $\mathrm{HO}_{\mathrm{x}}\left(\mathrm{HO}_{2} / \mathrm{OH}\right)(\mathrm{Bloss}$ et al., 2005); activating chlorine (McFiggans et al., 2002) and particularly bromine from sea-salt aerosol; and the reaction between IO and dimethyl sulphide (DMS) (Gravestock et al., 2005). The role of iodine in $\mathrm{O}_{3}$ and $\mathrm{Hg}$ depletion episodes in the Arctic polar spring is also a current research topic (Calvert and Lindberg, 2004a,b). Interest in iodine chemistry has been greatly stimulated in the last few years by the measurement of IO and OIO, at significant concentrations, in a number of geographical locations (Alicke et al., 1999; Allan et al., 2000, 2001; Saiz-Lopez and Plane, 2004).

Iodine is often enriched in marine aerosols by 2 to 3 orders of magnitude, compared with its relative abundance in sea salt (Duce et al., 1963). A recent study of the iodine speciation in aerosol samples from the south and north tropical Atlantic Ocean have shown that iodine, mostly in the form of iodate $\left(\mathrm{IO}_{3}^{-}\right)$, was enriched whereas bromine and chlorine were depleted. The enrichment factor of iodine in the fine aerosol mode was found to be an order of magnitude greater than that in the coarse mode (Baker, 2004).

The role of the higher iodine oxides $\left(\mathrm{I}_{\mathrm{x}} \mathrm{O}_{\mathrm{y}}\right)$ in the formation of new particles in coastal marine environments has also been widely discussed (Hoffmann et al., 2001; O'Dowd et al., 2002a; Jimenez et al., 2003; McFiggans et al., 2004). Although it is thought that most of newly-formed nanoparticles will be accommodated onto pre-existing marine aerosol, a fraction may be able to grow to detectable sizes (diameter

Published by Copernicus GmbH on behalf of the European Geosciences Union. 
$D>3 \mathrm{~nm}$ ) by the further uptake of condensable gaseous species and coagulation (Makela et al., 2002). The duration of such events can range from tens of minutes up to $8 \mathrm{~h}$. Particle bursts have been found at different coastal locations such as Western Europe (O'Dowd et al., 2002b, and references therein), Tasmania (Bigg and Turvey, 1978) and Antarctica (O’Dowd et al., 1997).

More recently, the detection of $\mathrm{I}_{2}$ at parts per trillion (ppt) levels by DOAS (Saiz-Lopez and Plane, 2004), and the experimental determination of its short photolytic lifetime (about 10s) have demonstrated that the molecule is a major source of reactive iodine in the atmosphere (Saiz-Lopez et al., 2004). Note that the sensitivity of the instrument and, therefore, the time resolution of the instrument does not allow measurements at the timescales at which photochemistry of the molecule occurs. Hence it might be reasonable to think of peak values larger than those reported here, because they are not captured at the time resolution of the DOAS. Emissions of $\mathrm{I}_{2}$ occur from coastal areas rich in macroalgae (and possibly also from open ocean sources Garland and Curtis, 1981). A mechanism for the release of $I_{2}$ from Laminaria macroalgal species has recently been suggested (McFiggans et al., 2004). Iodide ( $\mathrm{I}^{-}$) from sea-water is oxidised within the cell walls of the plant by hydrogen peroxide to form hypoiodous acid (HOI) (Kupper et al., 1998). HOI and $\mathrm{I}^{-}$ then equilibrate with $\mathrm{I}_{2}$ in aqueous solution (Truesdale et al., 1994). For $I_{2}$ to be liberated into the gas phase, the plant must be exposed to the atmosphere (at low tide) or covered by only a thin layer of water. $I_{2}$ is then likely to be the main contributor to the formation of condensable iodine oxide vapours, leading to the nucleation and growth to detectable sizes of the ultrafine particles observed at low tide. For example, a recent study concluded that the observed $I_{2}$ emissions at low tide provided a source of atomic iodine about $10^{3}$ times stronger than that of $\mathrm{CH}_{2} \mathrm{I}_{2}$, which was previously thought to be the main precursor of reactive iodine in the coastal MBL (McFiggans et al., 2004).

During daytime, $\mathrm{I}_{2}$ released into the marine boundary layer will be photolysed to I atoms, which react rapidly with $\mathrm{O}_{3}$ to form IO. The self reaction of IO forms OIO and $\mathrm{I}_{2} \mathrm{O}_{2}$ (Cox et al., 1999); the former may photodissociate to $\mathrm{I}_{2} \mathrm{O}_{2}$ (Ashworth et al., 2002), although this point is discussed further below. Both IO and OIO are presumably removed from the gas phase by uptake onto pre-existing aerosol surfaces, or initiate new particle formation by forming the higher oxides $\mathrm{I}_{2} \mathrm{O}_{\mathrm{y}}$, where $\mathrm{y}=2-5$ (McFiggans et al., 2000; Hoffmann et al., 2001; O'Dowd et al., 2002a,b,c; Jimenez et al., 2003; Burkholder et al., 2004). In fact, although laboratory (Jimenez et al., 2003; Burkholder et al., 2004; McFiggans et al., 2004) and theoretical (Begovic et al., 2004) work on new particle formation has been carried out, the detailed mechanism leading to the formation of iodine oxide nanoparticles in coastal environments remains an unsolved question. This is an important problem to solve because, if $\mathrm{I}_{2}$ emissions occur on a larger scale than just along Laminaria- rich coasts, then $\mathrm{I}_{2}$ could play a significant role in producing $\mathrm{CCN}$, and therefore impact on global radiative forcing and climate.

In this paper we use a coupled photochemical-aerosol growth model to investigate the role of $\mathrm{I}_{2}$ emissions in new particle formation. The model will first be used to show that the ratio of $I_{2}$ to IO observed by DOAS (Saiz-Lopez and Plane, 2004), during the NAMBLEX campaign at Mace Head, Ireland during July and August 2002, can only be explained if the iodine species are not distributed homogeneously along the $4.2 \mathrm{~km}$ path length of the instrument. The conclusion that the $\mathrm{I}_{2}$ emission is almost exclusively in the intertidal zone will then be validated against in-situ observations of $\mathrm{I}_{2}$ carried out by two quite different techniques Broad Band Cavity Ringdown Spectroscopy (BBCRDS), and Inductively-Coupled Plasma/Mass Spectrometry (ICP/MS).

\section{Model description}

The model used here contains the gas-phase iodine chemistry in our previous iodine model (McFiggans et al., 2000; Plane and Nien, 1991), with pertinent updates in kinetic and photochemical data, coupled to an aerosol coagulationcondensation algorithm (Jacobson, 1999) which is used to determine the growth of newly-formed iodine oxide particles. The particles are distributed between 50 size bins ( $D=0.6-460 \mathrm{~nm}$ ), where the volume of each successive bin increases by a factor of 1.5. We assume that the iodine condensing gases are non-volatile and every $\mathrm{I}_{2} \mathrm{O}_{\mathrm{x}}(\mathrm{x}=2,3$ and 4 ) formed is treated as a thermodynamically stable unit of the smallest size. Then, the semi-implicit subroutine calculates the coagulation kernel for each possible collision pair, starting with the Brownian coagulation rate for the transition regime taken from Jacobson (1999, page 446, Eq. 16.28), after (Fuchs, 1964). This follows assuming that the convective Brownian diffusion enhancement (page 446, Eq. 16.30), turbulent inertia (page 447, Eq. 16.35), turbulent shear (page 447, Eq. 16.36) and gravitational collection (page 447, Eq. 16.32) do not contribute significantly at the size range in question (roughly $1 \mathrm{~nm}$ to $2-3$ microns). The model also allows condensation of IO and OIO onto newly formed iodine particles. Condensation of $\mathrm{H}_{2} \mathrm{O}, \mathrm{H}_{2} \mathrm{SO}_{4}$ and organic vapours is not considered in this modelling study.

We assume that the smallest particles in the first size bin can be either $\mathrm{I}_{2} \mathrm{O}_{2}, \mathrm{I}_{2} \mathrm{O}_{3}$ or $\mathrm{I}_{2} \mathrm{O}_{4}$, produced from the recombination reactions $\mathrm{IO}+\mathrm{IO}$, $\mathrm{IO}+\mathrm{OIO}$ and $\mathrm{OIO}+\mathrm{OIO}$, respectively. The particle nucleation treatment in this model is based on the assumption that once the gas-phase iodine oxides species $\left(\mathrm{I}_{2} \mathrm{O}_{2}, \mathrm{I}_{2} \mathrm{O}_{3}\right.$ and $\left.\mathrm{I}_{2} \mathrm{O}_{4}\right)$ are formed they completely undergo the formation of small particles. Evaporation is not expected to occur, and so is not treated in the model. This assumption is based on laboratory studies of iodine oxide particle growth kinetics (Saunders and Plane, 2005), which show that the growth of these particles through 
coagulation and condensation proceeds at the collision frequency, in accord with the model scheme employed for this study. The material density of the small particles used here is $4 \mathrm{~g} \mathrm{~cm}^{-3}$ taken from (Daehlie and Kjekshus, 1964). The rate coefficient for $\mathrm{IO}+\mathrm{IO}$ is now well established to be $1 \times 10^{-10} \mathrm{~cm}^{3}$ molecule ${ }^{-1} \mathrm{~s}^{-1}$ (Sander et al., 2003). At atmospheric pressure, this reaction appears to have two channels: $\mathrm{I}_{2} \mathrm{O}_{2}(62 \pm 8 \%)$, and $\mathrm{OIO}+\mathrm{I}(38 \pm 8 \%)$ (Cox et al., 1999; Bloss et al., 2001), in good accord with recent work in our laboratory where a branching ratio for OIO production of $32 \pm 10 \%$ was measured (D. M. Joseph, personal communication, 2004). Here we assume $\mathrm{I}_{2} \mathrm{O}_{2}$ is formed with a $65 \%$ probability. A combination of quantum calculations on $\mathrm{I}_{2} \mathrm{O}_{3}$ and $\mathrm{I}_{2} \mathrm{O}_{4}$ and RRKM theory shows that the rate constants for IO + OIO and OIO + OIO should be about $2 \times 10^{-10}$ and $5 \times 10^{-11} \mathrm{~cm}^{3}$ molecule ${ }^{-1} \mathrm{~s}^{-1}$, respectively, at 1 atmosphere pressure and $290 \mathrm{~K}$. This rate of formation of $\mathrm{I}_{2} \mathrm{O}_{3}$ is in very good agreement with a recent experimental determination (J. Gomez-Martin, University of Bremen, personal communication, 2005).

One significant uncertainty in the gas-phase chemistry of iodine is the rate of OIO photolysis. The radical has a substantial absorption cross section between about 480 and $650 \mathrm{~nm}$ (Himmelmann et al., 1996), with bands that are rotationally unresolved and do not fluoresce (Ashworth et al., 2002; Bloss et al., 2001). However, it is not yet clear whether absorption leads to photodissociation to $\mathrm{I}_{+} \mathrm{O}_{2}$, or interconversion to the ground state followed by quenching. The $\mathrm{IO}+\mathrm{O}\left({ }^{3} \mathrm{P}\right)$ channel is not relevant here because the OIO absorption cross-section is comparatively small at wavelengths shorter than the $\sim 410 \mathrm{~nm}$ threshold (Misra and Marshall, 1998). Recent work in our laboratory indicates that the photolysis quantum yield for absorption at $562 \mathrm{~nm}$ is probably much lower than $10 \%$, although this may change at shorter wavelengths.

For the purpose of the present study, we have therefore determined an upper limit to the photolysis rate of OIO, and also assess the case where OIO does not photolyse in the lower troposphere $J_{\mathrm{OIO}}=0$. The upper limit is computed assuming that the photolysis quantum yield is $100 \%$ across all the absorption bands between 480 and $650 \mathrm{~nm}$. The photodissociation rate constant, $J_{\mathrm{OIO}}$, is then computed to be $0.48 \mathrm{~s}^{-1}$ for clear sky conditions during local noon at $53^{\circ} \mathrm{N}$ in July, assuming an atmospheric attenuation of $20 \%$ of the extraterrestrial flux (Houghton, 2002). In the model runs described below, this upper limit of $J_{O I O} O$ was reduced by $50 \%$ to a daytime average value of $0.24 s^{-1}$, which also takes account of the frequently cloudy conditions at Mace Head. We note that Burkholder and coworkers concluded that an upper limit of $J_{\mathrm{OIO}}<0.005 \mathrm{~s}^{-1}$ was necessary to allow significant particle production to occur in the MBL (Burkholder et al., 2004). However, that study assumed that particles were only produced by the dimerisation of OIO. Note that, as has been pointed out in Sect. 4.2, the particle formation is sensitive to the rate of photodissociation of OIO, especially at shorter

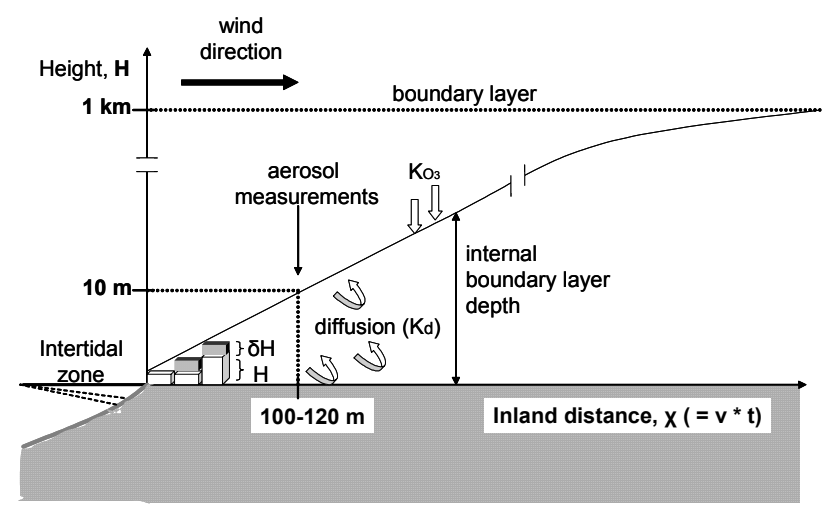

Fig. 1. Schematic of an evolving plume containing the gas molecules and particles offshore from the emissions point at the intertidal zone.

timescales. However, in this study this assumption is less sensitive since $\mathrm{I}_{2} \mathrm{O}_{2}$ is also considered a condensable unit and therefore the particle nucleation does not rely entirely on the participation of OIO.

The model is integrated using a variable stepsize fourthorder Runge-Kutta routine (Press et al., 1986). After each second the aerosol coagulation-condensation algorithm is used to update the growth of particles in response to the gasphase iodine chemistry. The uptake rate of IO, OIO, $\mathrm{I}_{2} \mathrm{O}_{2}$, $\mathrm{I}_{2} \mathrm{O}_{3}, \mathrm{I}_{2} \mathrm{O}_{4}$ and larger iodine oxide particles onto background marine aerosol (whose size distribution was measured during the NAMBLEX campaign), is calculated using uptake coefficients $\gamma$ of 1 for all species. For $\gamma=1$, this yields an uptake rate of around $3 \times 10^{-3} \mathrm{~s}^{-1}$ for IO and OIO. During the simulations described here, all iodine-containing species, except alkyl iodides, and $\mathrm{O}_{3}$ are allowed to vary. The mixing ratios of other species affecting the iodine chemistry are held constant at typical daytime values typical for Mace Head under maritime air mass conditions: $\mathrm{NO}_{2}=150 \mathrm{ppt}$, $\mathrm{NO}=30 \mathrm{ppt}, \mathrm{OH}=0.05 \mathrm{ppt}$ and $\mathrm{HO}_{2}=3 \mathrm{ppt}$ and $\mathrm{DMS}=100 \mathrm{ppt}$, $\mathrm{CH}_{2} \mathrm{I}_{2}=0.1 \mathrm{ppt}, \mathrm{CH}_{3} \mathrm{I}=3$ ppt, $\mathrm{CH}_{2} \mathrm{BrI}=0.15$ ppt.

In order to assess the potential for $\mathrm{I}_{2}$, released in the intertidal zone, to form iodine-containing aerosols which evolve into CCN over a period of about an hour, we use a box model with dilution parameterised as rate of entrainment from the background air. This is shown schematically in Fig. 1, for the case of an on-shore wind. $I_{2}$ is mixed into an air parcel with an internal boundary layer depth of a few metres, as it crosses the intertidal zone. The $\mathrm{I}_{2}$ source is then switched off once the air leaves the intertidal zone, and both iodinecontaining gases and particles are allowed to dilute into an evolving internal boundary layer of height $H$. A first-order dilution coefficient, $K_{d}\left(\mathrm{~s}^{-1}\right)$, is therefore introduced into the continuity equation for the iodine species, $[\mathrm{X}]$ :

$\frac{d[X]}{d t}=P_{i}-L_{i}[X]-K_{d}[X]$ 


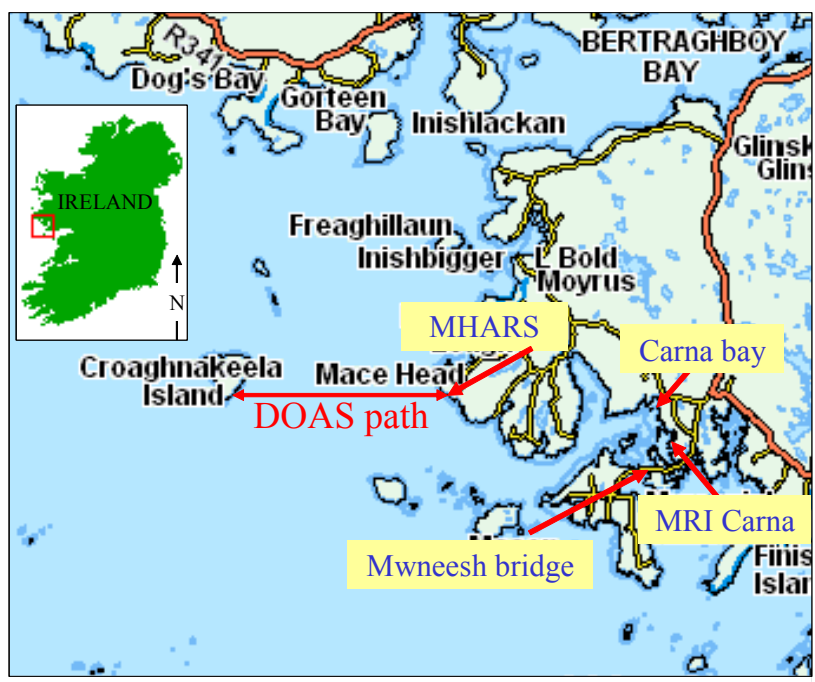

Fig. 2. Location of the DOAS light path at Mace Head and the different denuder sampling sites on the west coast of Ireland.

where $P_{i}$ and $L_{i}$ correspond to the chemical production and loss terms of $\mathrm{X}$, respectively. The horizontal distance $x$ covered by the air parcel is given by the product of the horizontal wind speed $v$ and the time $t$ since leaving the intertidal zone. We assume that $H$ increases linearly with $x$, with a constant slope $\alpha$ of about 0.1 . This is based on micro-meteorological data during NAMBLEX (Norton et al., 2005), which showed that the mean internal boundary layer depth was approximately $10 \mathrm{~m}$ about $100 \mathrm{~m}$ from the intertidal zone. The dilution coefficient, $K_{d}$, is then given by $\alpha \nu / H$.

Since the iodine chemistry causes significant depletion of $\mathrm{O}_{3}$ in the air parcel, replenishment of $\mathrm{O}_{3}$ from aloft is accounted for by adding an entrainment term to the continuity equation for $\mathrm{O}_{3}$ :

$\frac{d\left[\mathrm{O}_{3}\right]}{d t}=P_{\mathrm{O}_{3}}-L_{\mathrm{O}_{3}}+K_{\mathrm{O}_{3}}\left(\left[\mathrm{O}_{3}\right]_{o}-\left[\mathrm{O}_{3}\right]_{t}\right)$

where $\left[\mathrm{O}_{3}\right]_{o}$ is the background mixing ratio aloft, and $K_{\mathrm{O}_{3}}$ is an entrainment coefficient which is also equal to $\alpha \nu / H$.

\section{Field observations}

\subsection{Differential Optical Absorption Spectroscopy (DOAS)}

The DOAS instrument employed to make long-path measurements of $\mathrm{I}_{2}$ and IO has been described in detail previously (Saiz-Lopez and Plane, 2004). The transmitter was located at the Mace Head Atmospheric Research Station. The light beam was directed to Croaghnakeela Island, $4.2 \mathrm{~km}$ to the west, and folded back to Mace Head by a retro-reflector, therefore providing a total light path of $8.4 \mathrm{~km}$. As shown in Fig. 2, the light path ran mostly over the ocean, at a height of 4 to $10 \mathrm{~m}$. $\mathrm{I}_{2}$ and IO were detected from their optical differential absorption spectra in the $535-575 \mathrm{~nm}$ and $430-460 \mathrm{~nm}$, respectively, with a time resolution of $30 \mathrm{~min}$. The details of the de-convolution procedure have been given previously (Plane and Saiz-Lopez, 2006).

\subsection{Broadband Cavity Ring-Down Spectroscopy (BBCRDS)}

BBCRDS was used to make point measurements of OIO and $\mathrm{I}_{2}$ mixing ratios on the shoreline, approximately $10 \mathrm{me}$ tres inland from the observatory housing the DOAS. The BBCRDS spectrometer has previously been used in laboratory studies of $\mathrm{H}_{2} \mathrm{O}, \mathrm{NO}_{3}$ and $\mathrm{O}_{2}$ (Ball et al., 2001; Ball and Jones, 2003), and its adaptation for in-situ field measurements is discussed in a companion publication (Bitter et al., 2005a). Briefly, a Nd:YAG pumped dye laser was operated with rhodamine $6 \mathrm{G}$ dye to provide broadband radiation over a spectral range of $4 \mathrm{~nm}$ FWHM centred at $568 \mathrm{~nm}$. This light was coupled into a ringdown cavity composed of two high reflectivity mirrors $(\mathrm{R}=99.992 \%$ at $570 \mathrm{~nm}$; Los Gatos Research) which were purged with dry filtered nitrogen to prevent contamination of their optical surfaces. The total length of the cavity was $220 \mathrm{~cm}$ of which a central $180 \mathrm{~cm}$ section was open to the atmosphere. Light leaking from the cavity was detected in a time- and wavelength-resolved fashion by a 2-dimensional charge coupled device. Thus, a set of wavelength-resolved ringdown times was obtained from each BBCRDS observation, and atmospheric absorption spectra were calculated from observations performed with the cavity open to the atmosphere and whilst flushed with dry nitrogen.

The mixing ratios of the molecular absorbers were retrieved by fitting the absorption cross sections of OIO (Ashworth et al., 2002), $I_{2}$ (Saiz-Lopez et al., 2004) and the 5 vibrational overtones of water vapour (Coheur et al., 2002) to the differential structure in the atmospheric sample's absorption spectrum. Aerosol extinction was assumed to be a linear function of wavelength over the range of the present measurements. The instrument's sensitivity depends on the size of the molecular absorbers' differential cross sections and on the bandwidth and intensity of the laser output. Typical detection limits were 4 pptv and 20 pptv for OIO and $\mathrm{I}_{2}$, respectively, for a total observation time of 20 min including acquisition of the nitrogen flush spectra.

\subsection{Denuder sampling and Inductively Coupled Plasma- Mass Spectrometry (ICP/MS)}

Based on the specific reaction between starch and $\mathrm{I}_{2}$ (Holleman and Wiberg, 2001), a denuder sampling technique was developed to collect gaseous $\mathrm{I}_{2}$ from ambient air. Starch ( $2 \mathrm{mg} \mathrm{mL}^{-1}$ in ethanolic solution) was coated to the inner surfaces of brown glass tubes (inside diameter $\phi_{i}=6 \mathrm{~mm}$, outside diameter $\phi_{o}=9 \mathrm{~mm}$, length $=50 \mathrm{~cm}$ ). To produce a uniform starch coating of the inner denuder walls, four $0.5 \mathrm{~mL}$ samples of the coating solution were slowly instilled onto the rotating denuder. During the coating procedure the denuder 
tubes were dried by flushing $\mathrm{N}_{2}$ at a flow rate of $0.5 \mathrm{~L} \mathrm{~min}^{-1}$. Finally, the denuders were sealed with polypropylene (PP) end-caps.

At the measuring site, a volumetric ambient air flow of $500 \mathrm{~mL} \mathrm{~min}^{-1}$ was sucked through the denuder tubes. The sampling time varied between 30 and $60 \mathrm{~min}$. Once the sampling was complete, the open endings of the tubes were again sealed with PP-caps. In the laboratory, the iodine-amylose complex was extracted from the denuder walls with $4 \mathrm{~mL}$ of a TMAH-solution (TetraMethylAmmonium Hydroxide, 5\% by weight) at $90^{\circ} \mathrm{C}$ for $3 \mathrm{~h}$. Finally, the solution was diluted to $1 \%$ TMAH, $200 \mathrm{ppb}$ Tellurium were added as an internal standard and the iodine mixing ratio was finally determined by ICP-MS (PQ2 Turbo Plus, VG elemental, UK).

\subsection{Aerosol instrumentation}

The instrumentation for sub-micron aerosol measurement was located in a shipping container at the foot of the tower next to the research station. Air was drawn down a $150 \mathrm{~mm}$ bore, $22 \mathrm{~m}$ high, dual inlet sampling stack at a flow rate of $150 \mathrm{~L} \mathrm{~min}^{-1}$. Sampling alternated every hour between the top of the stack and an inlet at $7 \mathrm{~m}$ height. The flow rate was such that diffusional losses for sub-micron particles were minimised. Air was sub-sampled isokinetically from the main stack through a $40 \mathrm{~mm}$ bore stainless steel line, bent through a $1 \mathrm{~m}$ radius of curvature before running the full length of the container. A differential mobility particle sizer (DMPS) system comprising two Vienna type differential mobility analysers (DMAs) (Winklmayr et al., 1991), one TSI model 3025 condensation particle counter (CPC) and one TSI model 3010 CPC, using mass flow control with sheath to aerosol flow ratio of 10:1 was used to measure aerosol number distributions from 3 to $700 \mathrm{~nm}$ diameter. Particle distributions from 0.3 micron to 47 micron diameter were measured at the top of the $10 \mathrm{~m}$ tower using two commercial optical instruments. A Grimm (model 1.109) optical particle counter retrieved distributions from 0.3 to 6.5 micron diameter using backscatter, and a modified Particle Measurement Systems Forward Scattering Spectrometer Probe (FSSP-100) with a rotating base to maintain alignment with the prevailing wind was used to retrieve distributions from 0.5 to 47 microns in 16 channels.

\subsection{Sampling sites}

The DOAS, BBCRDS and aerosol instruments were positioned at Mace Head ( $\left.53^{\circ} 20^{\prime} \mathrm{N}, 9^{\circ} 54^{\prime} \mathrm{W}\right)$, whereas two other sampling sites were used to fill the starch denuders for later ICP/MS analysis: the Martin Ryan Marine Science Institute in Carna, Galway, (MRI-Carna), and Mweenish Bridge. These are located about $8 \mathrm{~km}$ southeast of the Mace Head research station (Fig. 2), and contain populations of kelp species that are very similar to those at Mace Head (Fucus vesiculosus and Laminaria digitata) (Yoon et al., 2004).
There is a higher density of the marine biota at Mweenish Bridge. All the denuder samples were taken during low tide in the intertidal zone, when the seaweeds were exposed to ambient air. A plant enclosure chamber filled with live kelps was also used for some of the measurements.

\section{Results and Discussion}

\subsection{Spatial distribution of $\mathrm{I}_{2}$ emission}

One objective of this study is to combine the long-path and in-situ measurements of $I_{2}$, together with the photochemical model, to determine the spatial distribution of $\mathrm{I}_{2}$ emission. The photochemical box model was therefore run to investigate two scenarios. First, $I_{2}$ is emitted uniformly along the optical path of the DOAS instrument. Second, $I_{2}$ emissions are limited to the intertidal zones at each end of the light path (i.e., the island and Mace Head foreshore - Fig. 2). The model results are then compared to the long-path averaged and in-situ observations of $\mathrm{I}_{2}$. Note that we begin here with the simple closed box model described in Sect. 2 . The effects of dilution by mixing through the boundary layer vertically will be considered later.

Figures $3 \mathrm{a}$ and $\mathrm{b}$ show model runs for $120 \mathrm{~min}$ around low tide $(\delta t=0)$. The broken and solid lines denote model runs for $J_{\mathrm{OIO}}=0.24$ and $0 \mathrm{~s}^{-1}$, respectively. The rate of $\mathrm{I}_{2}$ emission in the model follows a Gaussian distribution, peaking at low tide, with a standard width of $22 \mathrm{~min}$. In the box model runs we prescribe $\mathrm{I}_{2}$ mixing ratios so that the Gaussian distribution peak corresponds to measured mixing ratios either by DOAS or by in-situ techniques depending upon whether we test spatially distributed or hot-spot case scenarios. In the entraining box approach the model is initialized with a mixing ratio based on in situ observations made during the same campaign by BBCRDS. In the model run in Fig. $3 \mathrm{a}$, the $\mathrm{I}_{2}$ emission rate is scaled to generate the daytime peak $\mathrm{I}_{2}$ mixing ratio observed by the DOAS, which averaged $6.5 \mathrm{ppt}$ assuming that all the iodine species were uniformly distributed along the $4.2 \mathrm{~km}$ of the DOAS optical path. The corresponding values for IO and OIO are also plotted (I has been removed from Fig. 3a for clarity). Note that the IO mixing ratio reaches 13.5 and $11.7 \mathrm{ppt}$ for $J_{\mathrm{OIO}}=0.24$ and $0 \mathrm{~s}^{-1}$, respectively (this is because the photolysis of OIO to yield I, followed by oxidation by atmospheric $\mathrm{O}_{3}$, increases the IO mixing ratio). Hence, at low tide, the model predicts a $[\mathrm{IO}] /\left[\mathrm{I}_{2}\right]$ ratio of $\sim 2$, whereas the DOAS observes an average IO mixing ratio of $3 \mathrm{ppt}$, and hence an $[\mathrm{IO}] /\left[\mathrm{I}_{2}\right]$ ratio of $\sim 0.5$. The model predicts a rate of $\mathrm{O}_{3}$ depletion resulting from iodinemediated photochemistry of about $1 \mathrm{ppbh}^{-1}$, which is not very sensitive to $J_{\mathrm{OIO}}$. The initial conditions in the model are the same in Fig. 3b as in Fig. 6. Both show a similar trend of IO with respect to $\mathrm{I}_{2}$ : the IO mixing ratio decays less rapidly than $I_{2}$ because the rate of the $\mathrm{IO}$ self reaction (being its main sink) varies as $[\mathrm{IO}]^{2}$. 


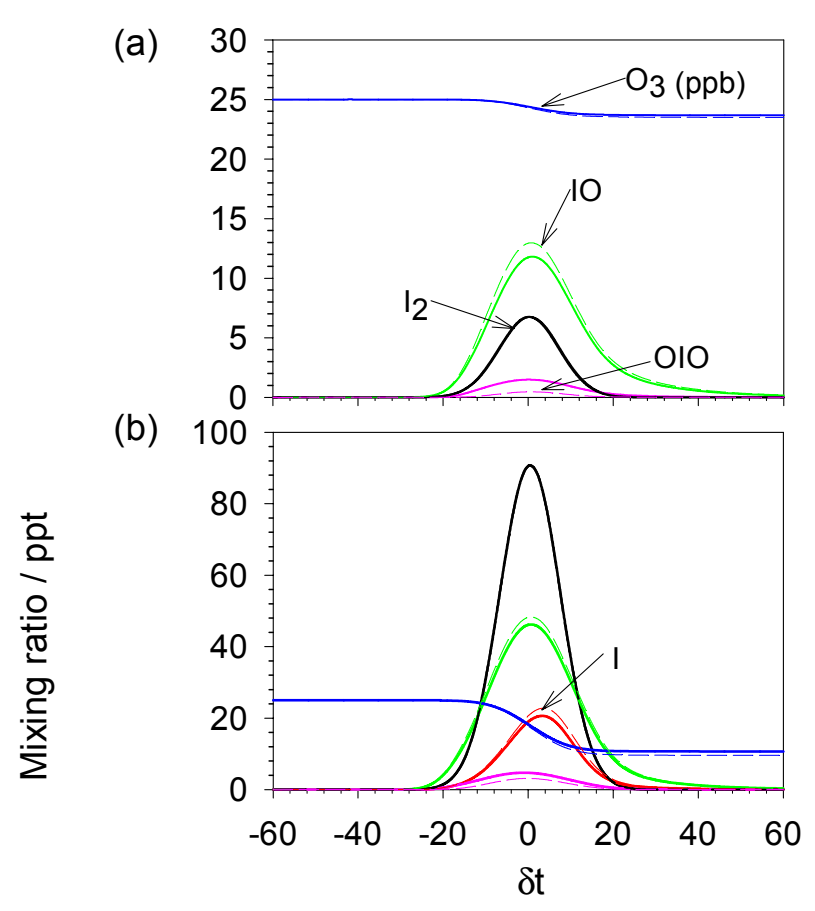

(c)

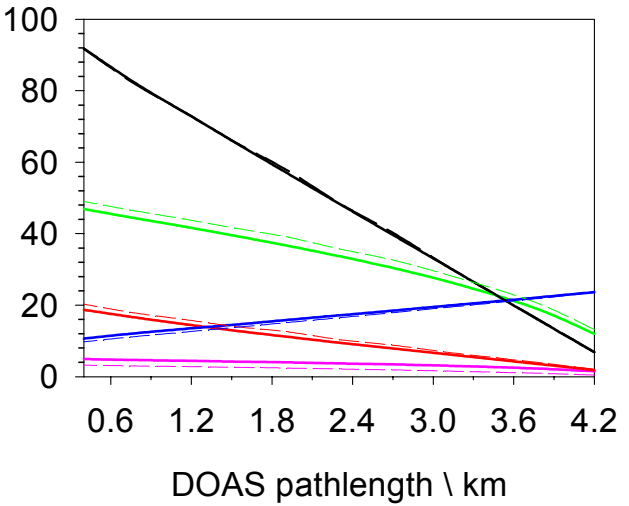

Fig. 3. Modelled iodine species and ozone depletion potential averaged over the $4.2 \mathrm{~km}$ of the DOAS path (a) and (b) in a box $320 \mathrm{~m}$ long. Each species mixing ratio is plotted during the $2 \mathrm{~h}$ simulation around low tide (Note that I is removed from panel (a) for clarity and $\delta t=0$ is equivalent to noon and minimum tidal height). Panel (c) shows the distribution of the different modelled compounds over the length of the DOAS optical path. The model was initialised with an $\mathrm{O}_{3}$ mixing ratio of $25 \mathrm{ppb}$ and the graph illustrates its depletion along the path. In the three figures the broken and solid lines indicate the model run for $J_{\mathrm{OIO}}=0.24$ and $0 \mathrm{~s}^{-1}$ respectively.

The OIO mixing ratio peaks at $\sim 0.46$ and $1.5 \mathrm{ppt}$ for $J_{\mathrm{OIO}}=0.24$ and $0 \mathrm{~s}^{-1}$, respectively. Note that even in the absence of photolysis the OIO mixing ratio does not reach a significant level, because of the fast recombination reaction with IO $\left(k=1.5 \times 10^{-10} \mathrm{~cm}^{3}\right.$ molecule $\mathrm{s}^{-1} \mathrm{~s}^{-1}$, J. GomezMartin, University of Bremen, personal communication, 2005). This is in accord with field measurements of OIO by DOAS, which during daytime are consistently below the
DOAS detection limit of 4 ppt (Allan et al., 2001; Saiz-Lopez and Plane, 2004). Note that this detection limit has been increased by a factor of 4 , following a change in the OIO absorption cross-section at $548.6 \mathrm{~nm}$ from $6.8 \times 10^{-17} \mathrm{~cm}^{-2}$ (see (Allan et al., 2001) for details), to $1.6 \pm 0.2 \times 10^{-17} \mathrm{~cm}^{-2}$ (personal communication, P. Spietz, University of Bremen and D. M. Joseph, University of East Anglia). Hence, even if $J_{\mathrm{OIO}}=0 \mathrm{~s}^{-1}$, OIO would be below the daytime minimum detectable amount of the DOAS instrument.

In order to produce an $[\mathrm{IO}] /\left[\mathrm{I}_{2}\right]$ ratio closer to that observed, the model was then initialised assuming that the $\mathrm{I}_{2}$ is only emitted along $8 \%$ of the DOAS light path, in a box of $320 \mathrm{~m}$ length (equivalent to two sections of $160 \mathrm{~m}$ at each end of the DOAS path, corresponding approximately to the intertidal zones). We estimated that a horizontal distance of $160 \mathrm{~m}$ for the intertidal zone is covered with seaweeds under low tidal periods, particularly during spring tides. The $\mathrm{I}_{2}$ emission rate is now increased in the smaller box, in order to generate the column density of $I_{2}$ observed by the DOAS. Figure $3 \mathrm{~b}$ shows that now the maximum mixing ratio of $\mathrm{I}_{2}$ in each end section peaks at $92 \mathrm{ppt}$, and the [IO] at $47 \mathrm{ppt}$, so that the $[\mathrm{IO}] /\left[\mathrm{I}_{2}\right]$ ratio is $\sim 0.5$, in agreement with the ratio observed by DOAS. Note that although [OIO] can now reach up to $5 \mathrm{ppt}$ in the intertidal sections, this corresponds to $0.4 \mathrm{ppt}$ averaged over the DOAS path, and hence would still be below the detection limit. The rate of $\mathrm{O}_{3}$ depletion resulting from iodine-mediated photochemistry is now predicted to be very substantial $\left(\sim 10 \mathrm{ppbh}^{-1}\right)$. However, this is very much an upper limit, because the closed box model does not allow for dilution (cf. below).

Figure $3 \mathrm{c}$ shows the predicted peak mixing ratios of the different iodine species as the path length over which the $\mathrm{I}_{2}$ emission occurs varies from $320 \mathrm{~m}$ to $4.2 \mathrm{~km}$ (the $\mathrm{I}_{2}$ emission rate is scaled so that the peak integrated column of $\mathrm{I}_{2}$ corresponds to that observed by the DOAS). The remaining $\mathrm{O}_{3}$ mixing ratio at the end of each model run is also shown. Note that although all the iodine species have higher mixing ratios if they are concentrated in a box of shorter length, the ratios of $\mathrm{I}, \mathrm{IO}$ and $\mathrm{OIO}$ to $\mathrm{I}_{2}$ decrease with increasing $\mathrm{I}_{2}$. There are two reasons for this. First, the recombination reactions $\mathrm{IO}+\mathrm{IO}, \mathrm{IO}+\mathrm{OIO}$ and $\mathrm{OIO}+\mathrm{OIO}$ are second-order in iodine oxide mixing ratio, so that their rates vary as $\left[\mathrm{IO}_{\mathrm{x}}\right]^{2}$. Second, because the resulting rate of iodine oxide particle formation is also a non-linear function of $\mathrm{I}_{2}$, uptake of IO and OIO on these new particles is faster at higher $\mathrm{I}_{2}$.

During NAMBLEX, daytime in-situ measurements of $\mathrm{I}_{2}$ were carried out by the BBCRDS instrument for a period of four days (Bitter et al., 2005 $\mathrm{b}^{1}$ ). During these nonconsecutive measurement days the $\mathrm{I}_{2}$ mixing ratio was found

\footnotetext{
${ }^{1}$ Bitter, M., Ball, S. M., Povey, I. M., Jones, R. L., Saiz-Lopez, A., and Plane, J. M. C.: Measurements of $\mathrm{NO}_{3}, \mathrm{~N}_{2} \mathrm{O}_{5}$, OIO, $\mathrm{I}_{2}$, water vapour and aerosol optical depth by broadband cavity ringdown spectroscopy during the NAMBLEX campaign, Atmos. Chem. Phys. Discuss., in preparation, 2005 b.
} 


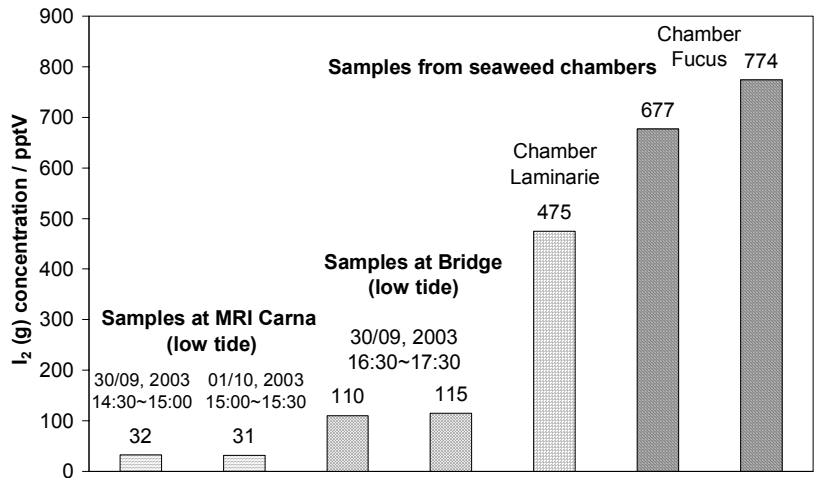

Fig. 4. $I_{2}$ mixing ratios observed by a denuder system, for several different locations around the Mace Head area and during seaweedchamber experiments in September 2003.

to increase as sea level fell (see lower panels in Fig. 9), in agreement with the DOAS observations (Saiz-Lopez and Plane, 2004). A mixing ratio peak of $94 \mathrm{ppt}$ was reached on 16 August (DOY 228) in the late afternoon/early evening when the solar radiation intensity has already decreased and photodissociation of $I_{2}$ is reduced. In addition to low tide periods, it has also been proposed that solar irradiance together with warmer temperatures enhances biological activity and therefore biogenic emissions at marine coastal locations (Carpenter et al., 1999). Hence, $I_{2}$ emissions are expected to be more accentuated when low water periods coincide with maximum solar radiation exposure.

Figure 4 shows the denuder tube measurement results at several locations (Fig. 2). At Mweenish Bridge, $I_{2}$ mixing ratios up to $115 \mathrm{ppt}$ were measured in the mid-afternoon during low tide periods, about 3 times higher than those at the MRI-Carna site where the density of seaweeds is lower. In addition, the experimental set up at Mweenish Bridge was such that there was a shorter vertical distance between the seaweed and the denuder sampler inlets. This is consistent with a vertical $\mathrm{I}_{2}$ mixing ratio gradient caused by its rapid photolysis during daytime. Also shown in Fig. 4 are the results of the chamber experiments, performed in September 2003, whereas the NAMBLEX campaign took place in 2002. The $I_{2}$ mixing ratio was about one order of magnitude higher than ambient, when the chamber was filled with fresh macroalgae.

In summary, the DOAS measurements when interpreted by the box model indicate that the daytime peak mixing ratio of $\mathrm{I}_{2}$ averaged about $92 \mathrm{ppt}$ at low tide, and that this was concentrated in a box about $320 \mathrm{~m}$ long (or two sections of $160 \mathrm{~m}$ at each intertidal zone along the light path). This $I_{2}$ mixing ratio is consistent with the in-situ daytime measurements by both the BBCRDS and denuder techniques, which range from 30 to $115 \mathrm{ppt}$, depending on sampling site.

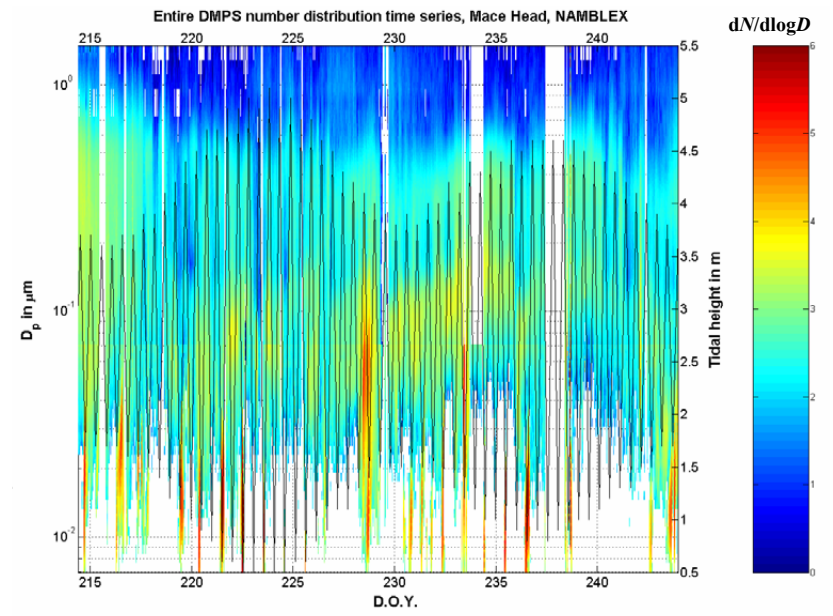

Fig. 5. DMPS particle size distribution series together with tidal height. Note that the unit of the colour-coded bar is an exponential.

\subsection{Ultrafine particle formation}

New particle formation events were observed on almost every day during the NAMBLEX campaign. These events only occurred during daytime, and tended to coincide with low tide. The peak particle number density reached more than $6 \times 10^{5} \mathrm{~cm}^{-3}$ on occasion (the most intense formation was on DOY 222, 10 Aug), though normally the bursts were more modest, reaching around 2 to $3 \times 10^{4} \mathrm{~cm}^{-3}$. Figure 5 shows the DMPS size distribution time series during the NAMBLEX campaign. The duration of the particle formation event was variable, lasting from several tens of minutes to more than 6 hours (the longest continuous formation was observed on DOY 216, 4 Aug), as was the size to which the particles had grown by the time they reached the sampling point. For instance, on DOY 222, no new particles had grown to larger than $8 \mathrm{~nm}$ before reaching the measurement location. However, on DOY 216, freshly formed particles had grown to a maximum of around $15 \mathrm{~nm}$ prior to reaching the measurement location, indicating a more distant source region. The trend was generally followed where the more persistent formation was associated with a greater maximum size but lower maximum mixing ratio, compared with the most intense formation events. Both features are strongly dependent on the prevailing local wind direction and the source location.

Regarding the vertical distribution, independently measured (TSI 3025 CPC) particle number mixing ratios measured at $7 \mathrm{~m}$ and $22 \mathrm{~m}$ exhibited little difference between the two heights. Further investigation of this difference showed that it is dependent on wind direction, thus indicating that the vertical distribution of the particles is dependent on the location of the source region.

Figure 6 shows a two hour simulation in the box model of the iodine oxide particles that would have been produced 


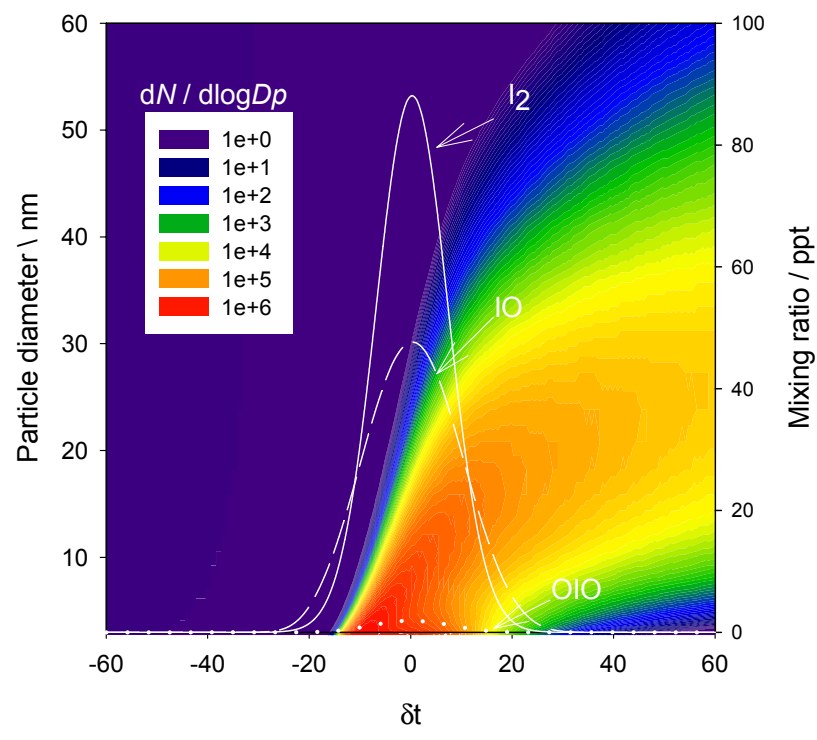

Fig. 6. Modelled contour plot of the new particle production and its size distribution during a $2 \mathrm{~h}$ simulation. $2 \mathrm{~h}$ simulation. Note that $\delta t=0$ is equivalent to noon and minimum tidal height). The model runs assuming typical clean air coastal mixing ratios of alkyl iodides and the locally observed $\mathrm{I}_{2}$, and predicted $\mathrm{IO}$ and OIO mixing ratio levels.

from the model run in Fig. $3 b$ - i.e., where the $I_{2}$ emission is concentrated in a box $320 \mathrm{~m}$ long. The predicted particle size distribution $(D=3-60 \mathrm{~nm})$ is plotted as a function of time around low tide $(\delta t=0$ is equivalent to noon and minimum tidal height), together with $\mathrm{I}_{2}$, IO and OIO. Note that these model runs include heterogeneous loss of the iodine oxides not only to the newly-formed ultrafine particles, but also to background aerosol. Figure 6 shows the maximum mixing ratio of ultrafine particles is correlated to the peak $\mathrm{I}_{2}$ emission, as expected because of the rapid photolysis of $\mathrm{I}_{2}$. Initially, there is not a significant contribution from the bigger sizes (i.e. $D>10 \mathrm{~nm}$ ) to the total number of particles. However, as condensation and coagulation cause the growth and removal of the smallest particles, about $20 \mathrm{~min}$ after the first particles appear the most abundant particle size is greater than $10 \mathrm{~nm}$. Of course, this zero-dimensional box model assumes no mixing and dilution as the air parcel is transported away from the intertidal zone.

We now consider the effect of dilution by using the box model with entrainment described in Section 2 and shown schematically in Fig. 1. Figure 7 shows the time-resolved mixing ratio of the iodine species and $\mathrm{O}_{3}$ when simulating the transport of the air parcel away from the emission source, for a period of $5 \mathrm{~min}$. Note that given the $100-120 \mathrm{~m}$ distance from the emissions source and typical horizontal wind speed, the air parcel would take less than 1 minute to reach the research station where the aerosol measurements were made. In this case, the model is initialised with an $\mathrm{I}_{2}$ mixing ratio of $90 \mathrm{ppt}$, consistent with the in situ observations. The broken

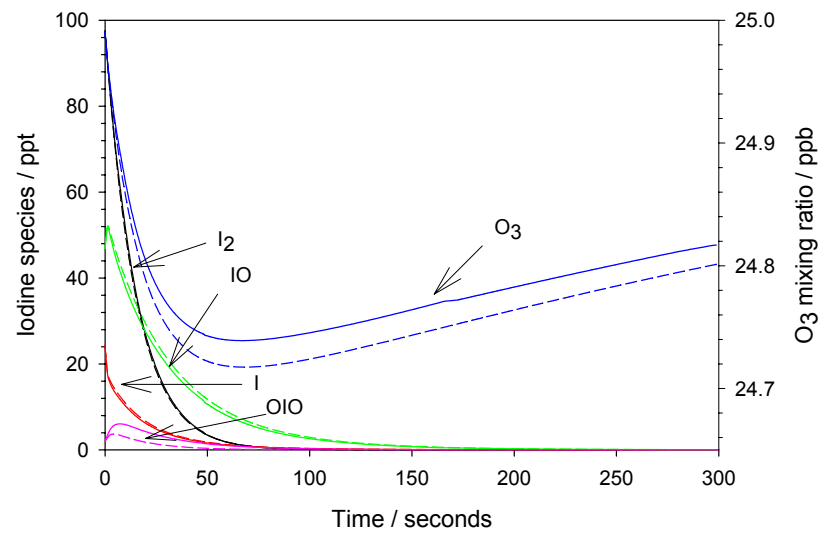

Fig. 7. Fig.7 Model simulation of iodine species and $\mathrm{O}_{3}$ for a box model with entrainment where the plume is allowed to evolve offshore from the emissions source. The broken and solid lines indicate the model run for $J_{\mathrm{OIO}}=0.24$ and $0 \mathrm{~s}^{-1}$ respectively.

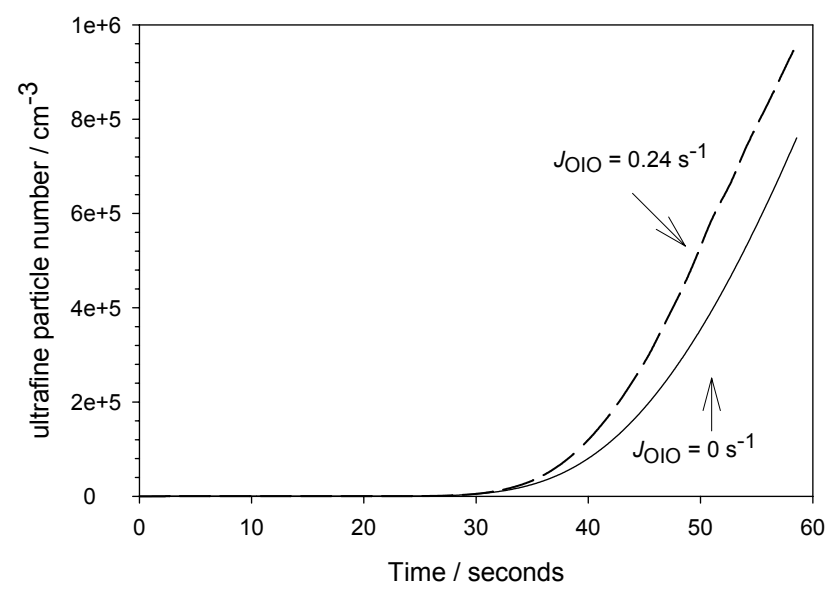

Fig. 8. Ultrafine particle number for a $1 \mathrm{~min}$ simulation. The broken and solid lines denote $J_{\mathrm{OIO}}=0.24$ and $0 \mathrm{~s}^{-1}$ respectively.

and solid lines in Fig. 7 correspond to $J_{\mathrm{OIO}}=0.24$ and $0 \mathrm{~s}^{-1}$, respectively. As expected, the $\mathrm{IO}$ and I mixing ratios are slightly higher for the upper limit to $J_{\mathrm{OIO}}$, since OIO photolyses to $\mathrm{I}+\mathrm{O}_{2}$, and there is also a greater $\mathrm{O}_{3}$ depletion. However, a marked difference with the zero-dimensional model (Fig. 3b) is that $\mathrm{O}_{3}$ depletion is much smaller because of mixing of $\mathrm{O}_{3}$ from aloft. In Fig. 7, at the beginning of the run, the $\mathrm{O}_{3}$ loss due to iodine chemistry $\left(\mathrm{I}+\mathrm{O}_{3}\right)$ is $0.12 \% \mathrm{~s}^{-1}$, but this decreases as the gas-phase iodine disappears; a partial recovery is then observed during the 5 min simulation as a result of entrainment. Within an hour the $\mathrm{O}_{3}$ mixing ratio would recover to background levels as the iodine species dilute in an expanding air mass and/or are removed from the gas phase.

$J_{\mathrm{OIO}}$ also affects the rate of formation of new ultrafine particles. In one of the sensitivity studies we consider OIO to photodissociate to $\mathrm{I}+\mathrm{O}_{2}$ (Ashworth et al., 2002). Therefore, 
(a)
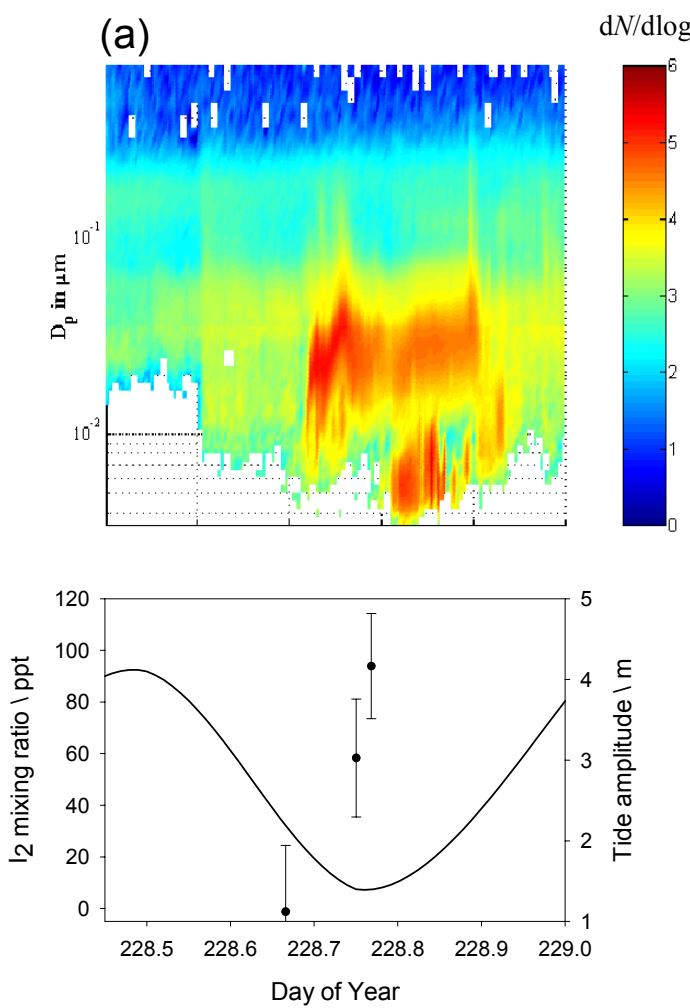

(b)
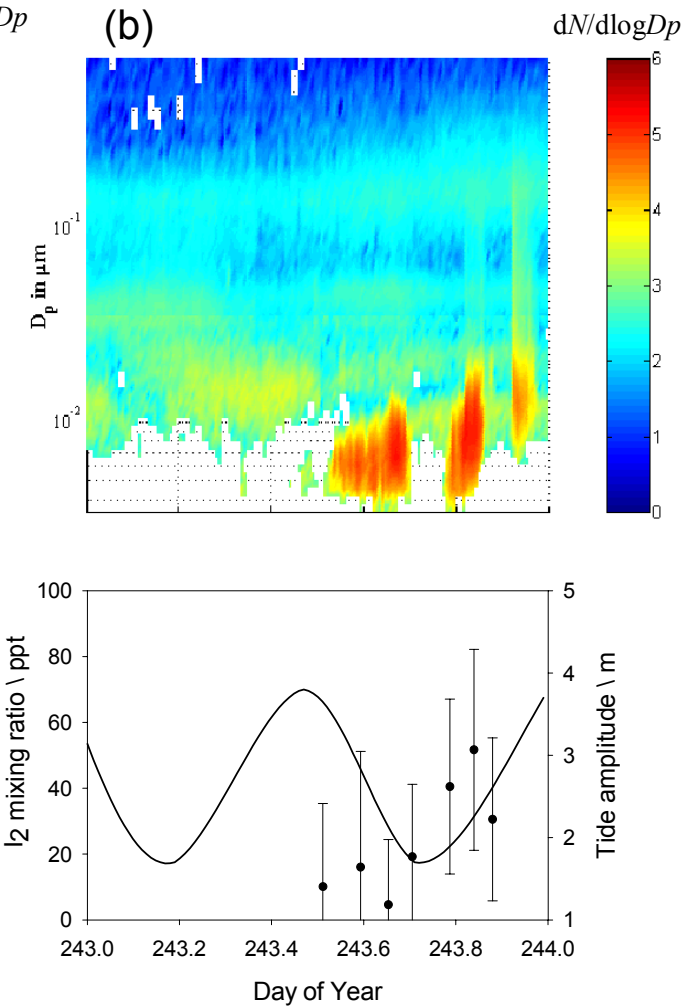

Fig. 9. Time series of two days of simultaneous observations of $I_{2}$ by BBCRDS together with tidal height, and dry particle size distributions at Mace Head at low tide conditions. Note that sunset times are 228.80 and 228.83 for data in panel (a) and (b) respectively.

at high $J_{\mathrm{OIO}}$ the formation of the IO dimer will be the dominant particle production channel and as we assume $\mathrm{I}_{2} \mathrm{O}_{2}$ as a condensable unit the rate of particle production at short timescales is larger for high $J_{\mathrm{OIO}}$. Figure 8 shows a 1 minute simulation of the generation of ultrafine particles. For instance, after $40 \mathrm{~s}$ of simulation the number of ultrafine particles generated with $J_{\mathrm{OIO}}=0.24 \mathrm{~s}^{-1}$ is about $30 \%$ higher than for a case of JOIO $=0 \mathrm{~s}^{-1}$. However, after a few minutes of simulation the total number of new particles is only $4.5 \%$ smaller for $\mathrm{JOIO}=0 \mathrm{~s}^{-1}$. This model run demonstrates that the new particle formation rate is strongly non-linear. The number density of new particles formed at short times $(<1 \mathrm{~min})$ is also sensitive to the branching ratio of the IO self-reaction, but again this sensitivity diminishes at longer times, as all the iodine oxides formed from the emitted $\mathrm{I}_{2}$ end up as particulate iodine.

It has been proposed recently that $I_{2}$ should be the main precursor of reactive iodine and ultrafine particles in the MBL at a location such as Mace Head (Saiz-Lopez and Plane, 2004; McFiggans et al., 2004; McFiggans, 2005). During NAMBLEX, in-situ simultaneous observations of $I_{2}$ by the BBCRDS technique together with a particle burst were carried out (for the first time). Figures $9 a$ and $b$ show the time correlation between the daytime release of $I_{2}$ at low water and the local production of new particles at Mace
Head. Both episodes take place during late afternoon/early evening when $\mathrm{I}_{2}$ would be photolysed, initiating the chain of reactions leading to the formation of condensable higher iodine oxides and the production of detectable particles. It should be noted that in Fig. 9b, for instance, the gaps with no particles at low tide were correlated to periods of variable wind direction at the measurement site, when different air masses were being sampled. In Fig. $9 \mathrm{~b}$ the particle burst begins during high tide. This can be explained either if the particles reaching the sampling point proceed from a different location around Mace Head, other than the nearest shoreline in front of Mace Head. It must also be considered that the tide can be higher and still allow nucleation if the wind is from sectors where the kelp beds extend further up the shore. Note that high tide was still fairly low (see Fig. 9b) and that it was a day of highly variable local meteorology, in particular in terms of wind direction. A burst of smaller particles then occurred later during low water, together with some growth of the larger particles. This suggests that there was a combination of particles emitted from the near shoreline and from more distant sources. Also in Fig. 9a it should be noted that the number of particles of $\mathrm{D}<10 \mathrm{~nm}$ drops during low tide, when photolysis ceases after sunset (around 20:00 LT).

In an attempt to replicate the particle bursts measured at Mace Head over a low tide cycle, the model was initialised 
(a)

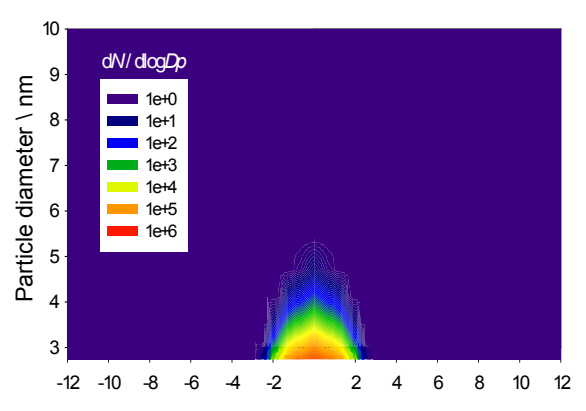

$\delta$

(b)

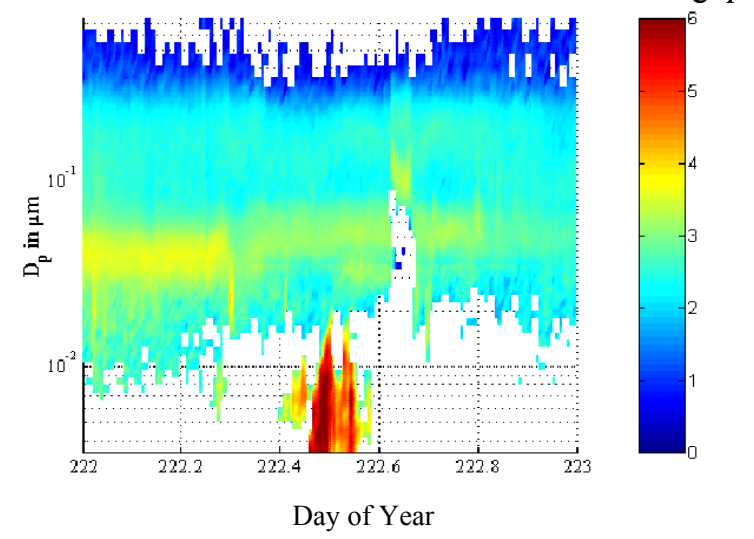

Fig. 10. (a) model simulation of the particle size distribution during a noon low tide particle burst.Note that $\delta t$ is in hours. (b) size distribution measurements on DOY 222, 10 August, as measured by the DMPS instrument. Note that the unit of the colour-coded bar is an exponential.

with $\mathrm{I}_{2}$ and allowed to run for $40 \mathrm{~s}$ to obtain the particle size distribution. This was subsequently repeated for different $\mathrm{I}_{2}$ mixing ratios to simulate the variation of $\mathrm{I}_{2}$ during low tide around midday. In Fig. 10a the model output for the particle distribution is plotted against time ( $\delta t=0$ is equivalent to noon and minimum tidal height). For the results in Fig. 10a, the $\mathrm{I}_{2}$ emission will follow a Gaussian distribution resulting in different peak mixing ratios depending on the strength of the emission. In the $\mathrm{x}$-axis the $\mathrm{dt}$ is in hours as opposed to Figs. $3 \mathrm{~b}$ and 6 where it is in minutes. This is compared in Fig. 10b with the dry particle size distribution for DOY 222, 10 August. As can be seen, the number of ultrafine particles at $\delta t=0$, when the iodine emissions are highest, is of the order of $10^{4}-10^{5} \mathrm{~cm}^{-3}$ which is around the level at which the bursts normally occur. Note that the timescale $(40 \mathrm{~s})$ does not appear to be sufficient for the particles to grow in significant numbers to diameters larger than $4-5 \mathrm{~nm}$. This is generally the case with nanoparticle observations at Mace Head, as the time required (over $1 \mathrm{~min}$ ) for the newly formed particles to evolve to bigger sizes is normally longer than the transit time from the emission source to the sampling point. Both modelled and measured particle size distributions agree reasonably well assuming that the emission point is about

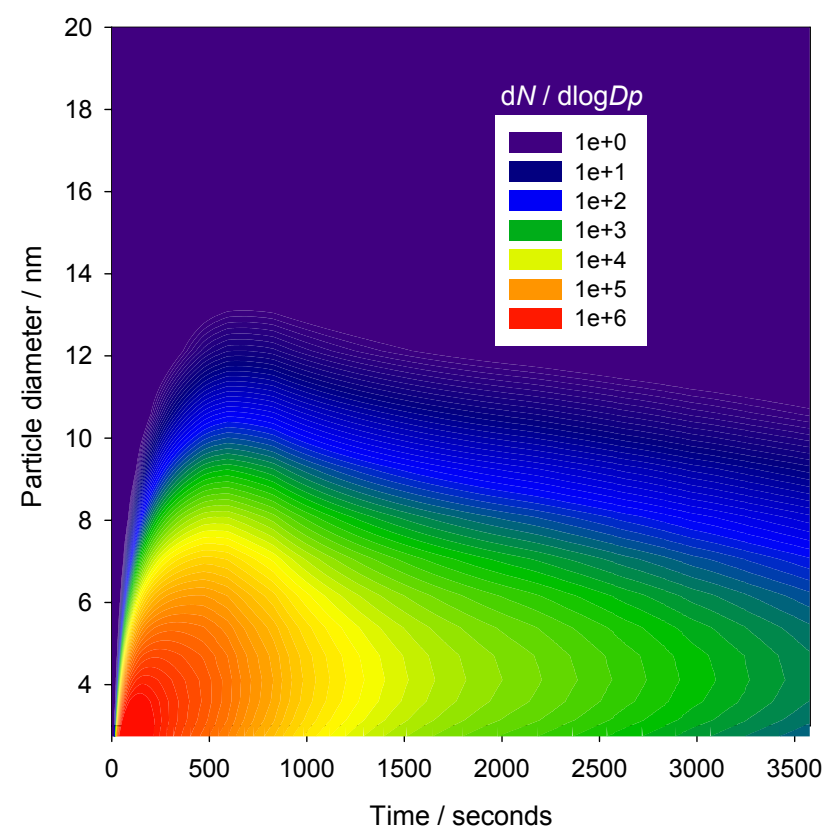

Fig. 11. $1 \mathrm{~h}$ model run of the particle size distribution for an evolving plume from the point of emission. The model is initialised with in-situ measured mixing ratios of the iodine species, which are then allowed to dilute into the evolving plume.

100-120 m distant. If the particle bursts occurred at a different location (e.g. a coastal area upwind of Mace Head and/or Croaghnakeela Island - Fig. 2), the timescale to reach the sampling point would increase by over an order of magnitude, allowing the ultrafine particles to evolve to larger sizes by the time they are observed at the at Mace Head. Note that the assumption made in this model that $\mathrm{I}_{2} \mathrm{O}_{2}$ participates as a condensable unit in the iodine particle nucleation is key for the reproduction of the particle formation at short timescales (e.g. about $1 \mathrm{~min}$ ). The sensitivity study carried out without including $\mathrm{I}_{2} \mathrm{O}_{2}$ in the particle nucleation shows a significant reduction in the particle formation at this timescale. Therefore, the results are sensitive to this assumption, showing that more work is needed to clarify the roles of $\mathrm{I}_{2} \mathrm{O}_{2}, \mathrm{I}_{2} \mathrm{O}_{3}$ and $\mathrm{I}_{2} \mathrm{O}_{4}$ in new particle formation.

Finally, the box model with entrainment is used to assess the potential of the iodine oxide particles to grow into $\mathrm{CCN}$ as the air parcel travels onshore. In this case the model was initialised as before, and then run for $1 \mathrm{~h}$ allowing the parcel to dilute up to a boundary layer height of $1 \mathrm{~km}$ over a horizontal distance of about $14 \mathrm{~km}$ for a given wind speed of $4 \mathrm{~m} \mathrm{~s}^{-1}$. Note that the internal boundary layer depth (Stull, 1988 ) is derived from vertical mixing measurements at the site and the subsequent evolution of the boundary layer is assumed to be linear based on these meteorological observations. However, we do not have measurements of how the vertical mixing developed $14 \mathrm{~km}$ inland. Figure 11 illustrates the evolution of the particle size distribution, showing the 
particle number decreasing as they evolve to bigger diameters. Only a few hundred particles would grow up to sizes over $10 \mathrm{~nm}$, whereas most remain below that particle diameter. If the minimum size to consider particles as CCN is typically $60 \mathrm{~nm}$, in this case the iodine oxide particle burst appears to make a minor contribution to potential CCN. However, the model does not include the growth of the particles by the uptake of other condensable vapours such as $\mathrm{H}_{2} \mathrm{O}$ and $\mathrm{H}_{2} \mathrm{SO}_{4}$, since very little is known about the properties of the iodine oxide particles in this regard. Thus the present model prediction of the total number of particles is probably valid, and the predicted growth is most likely a lower limit. In the model an upper limit to the first-order loss rate of new particles due to intermodal coagulation is approximated as the first order loss rate of monomer units. Intermodal coagulation represents the integral of the coagulation kernel convolved with the number distribution for larger (measured) aerosol. The value we have chosen represents an upper limit to the loss rate since, as the freshly nucleated particles grow, their coagulation loss rate to the larger particles will only decrease below that for the monomer units. The reason for this treatment is that we use measured large mode aerosol for constraint, and the nucleation and growth description for the small aerosol does not interact with the measured aerosol. The coagulation to pre-existing aerosol does not greatly affect the result.

Figure 11 shows that over $110 \mathrm{~cm}^{-3}$ of iodine-containing particles remain after the $1 \mathrm{~h}$ run, assuming these are fully mixed vertically up to $1 \mathrm{~km}$. It must be noted that the model runs do not assume recycling of iodine from particles. However, sensitivity studies have been carried out including iodine recycling on aerosols via uptake of $\mathrm{HOI}$ and $\mathrm{IONO}_{2}$ (the rate-limiting step in the recycle process), followed by subsequent release of $\mathrm{IBr}$ and $\mathrm{ICl}$. Incorporating recycling has an insignificant effect on model runs of a few minutes. This is assuming a scenario of freshly generated sea-salt aerosols, where no halogen processing is occurring at time zero. However, when running the model for $1 \mathrm{~h}$ with iodine recycling, the size-integrated particle number density is now 3 times greater, reaching up to $300 \mathrm{~cm}^{-3}$. Of course, in this scenario the role of the $\mathrm{I}_{2} \mathrm{O}_{2}$ dimer as a condensable unit is crucial, since any $\mathrm{IO}$ formed as a consequence of $\mathrm{IBr}$ and ICl photolysis, when there is no $I_{2}$ around, will react with itself and contribute to the particle formation in the model. For instance, when the model is run without $\mathrm{I}_{2} \mathrm{O}_{2}$, the particle formation is less sensitive to iodine recycling in aerosols. If we take a typical background aerosol loading for a clean marine environment of $\sim 100-500 \mathrm{~cm}^{-3}$ (O'Dowd et al., 2002b), then there has been a significant contribution from iodine oxide particles to the background aerosol, and these may grow into $\mathrm{CCN}$ in the presence of additional condensable vapours. Indeed, a recent airborne experiment has produced clear evidence for the relatively large scale of new particle formation events in this coastal zone (O’Dowd, 2002).

\section{Conclusions}

An iodine chemistry model has been used to analyse measurements of $\mathrm{I}_{2}$ in the coastal MBL, which were made during the NAMBLEX campaign by three different techniques: long-path DOAS, BBCRDS and ICP/MS. This exercise demonstrates that the $\mathrm{I}_{2}$ (and IO and OIO) were almost certainly located above the intertidal zones at each end of the DOAS optical path. The formation of ultrafine particles, following the emission of $\mathrm{I}_{2}$ when macroalgae are exposed to the atmosphere at low tide, has been modelled and compared with observed particle bursts. The simulated particle bursts produce a maximum number of ultrafine particles $\left(D=3-10 \mathrm{~nm}\right.$ ) exceeding $10^{5} \mathrm{~cm}^{-3}$, in good accord with the observations. Since we also report the first combined measurements of in-situ $\mathrm{I}_{2}$ and ultra-fine aerosol, this study appears to confirm that $I_{2}$ is the major precursor of these particle bursts. The model also shows that the iodine oxide nanoparticles can grow to make an important contribution, at least on a regional scale, to to viable condensation nuclei. Finally, the uncertainty surrounding the photolysis of the OIO radical was explored by assigning an upper limit to $J_{\mathrm{OIO}}$ (assuming absorption in the visible bands the molecule leads to $100 \%$ dissociation), and also considering the case that the photolysis yield is zero. This shows that the rate of new particle formation is only slightly sensitive to $J_{\mathrm{OIO}}$, because the recombination of OIO with IO and itself is competitive with photolysis when the concentration of iodine oxides is relatively large above the intertidal zone. The rate of $\mathrm{O}_{3}$ depletion increases with $J_{\mathrm{OIO}}$, but even at the upper limit the effect is very localized and quickly disappears through entrainment of $\mathrm{O}_{3}$-rich air from higher in the boundary layer.

Acknowledgements. This work was supported by the UK National Environment Research Council. The authors wish to thank D. Heard (U. Leeds) for leading the NAMBLEX field campaign, R. Saunders (UEA) and Roberto Sommariva (NOAA) for helpful discussions.

Edited by: D. Heard

\section{References}

Alicke, B., Hebestreit, K., Stutz, J., and Platt, U.: Iodine oxide in the marine boundary layer, Nature, 397, 572-573, 1999.

Allan, B. J., McFiggans, G., Plane, J. M. C., and Coe, H.: Observations of iodine monoxide in the remote marine boundary layer, J. Geophys. Res.-Atmos, 105, 14 363-14 369, 2000.

Allan, B. J., Plane, J. M. C., and McFiggans, G.: Observations of OIO in the remote marine boundary layer, Geophys. Res. Lett., 28, 1945-1948, 2001.

Ashworth, S. H., Allan, B. J., and Plane, J. M. C.: High resolution spectroscopy of the OIO radical: Implications for the ozonedepleting potential of iodine, Geophys. Res. Lett., 29, 1456 , doi:10.1029/2001GL013 851, 2002. 
Baker, A. R.: Inorganic iodine speciation in tropical Atlantic aerosol, Geophys. Res. Lett., 31, L23S02, doi:10.1029/2004GL020 144, 2004.

Ball, S. M. and Jones, R. L.: Broad-band cavity ring-down spectroscopy, Chem. Rev., 103, 5239-5262, 2003.

Ball, S. M., Povey, I. M., Norton, E. G., and Jones, R. L.: Broadband cavity ringdown spectroscopy of the $\mathrm{NO}_{3}$ radical, Chem. Phys. Lett., 342, 113-120, 2001.

Begovic, N., Markovic, Z., Anic, S., and Kolar-Anic, L.: Modelling the formation of biogenic iodine in marine aerosols, Environ. Chem. Lett., 2, 65-69, 2004.

Bigg, E. K. and Turvey, D. E.: Sources of atmospheric particles over Australia, Atmos. Environ., 12, 1643-1655, 1978.

Bitter, M., Ball, S. M., Povey, I. M., and Jones, R. L.: A broadband cavity ringdown spectrometer for in-situ measurements of trace gases, Atmos. Chem. Phys., 5, 2547-2560, 2005a.

Bloss, W. J., Rowley, D. M., Cox, R. A., and Jones, R. L.: Kinetics and products of the IO self-reaction, J. Phys. Chem. A, 105, 7840-7854, 2001.

Bloss, W. J., Lee, J. D., Johnson, G. P., Sommariva, R., Heard, D. E., Saiz-Lopez, A., Plane, J. M. C., McFiggans, G., Coe, H., Flynn, M., Williams, P., Rickard, A. R., and Fleming, Z.: Impact of halogen monoxide chemistry upon boundary layer $\mathrm{OH}$ and $\mathrm{HO}_{2}$ concentrations at a coastal site, Geophys. Res. Lett., 32, 2005.

Burkholder, J. B., Curtius, J., Ravishankara, A. R., and Lovejoy, E. R.: Laboratory studies of the homogeneous nucleation of iodine oxides, Atmos. Chem. Phys., 4, 19-34, 2004.

Calvert, J. G. and Lindberg, S. E.: The potential influence of iodinecontaining compounds on the chemistry of the troposphere in the polar spring. I. Ozone depletion, Atmos. Environ., 38, 50875104, 2004a.

Calvert, J. G. and Lindberg, S. E.: The potential influence of iodinecontaining compounds on the chemistry of the troposphere in the polar spring. II. Mercury depletion, Atmos. Environ., 38, 51055116, 2004b.

Carpenter, L. J.: Iodine in the marine boundary layer, Chem. Rev., 103, 4953-4962, 2003.

Carpenter, L. J., Sturges, W. T., Penkett, S. A., Liss, P. S., Alicke, B., Hebestreit, K., and Platt, U.: Short-lived alkyl iodides and bromides at Mace Head, Ireland: Links to biogenic sources and halogen oxide production, J. Geophys. Res.-Atmos, 104, 16791689, 1999.

Chameides, W. L. and Davis, D. D.: Iodine - Its possible role in tropospheric photochemistry, J. Geophys. Res.-Atmos, 85, 73837398, 1980.

Coheur, P. F., Fally, S., Carleer, M., Clerbaux, C., Colin, R., Jenouvrier, A., Merienne, M. F., Hermans, C., and Vandaele, A. C.: New water vapor line parameters in the $26000-13000 \mathrm{~cm}(-1)$ region, J. Quant. Spectrosc. Radiat. Transf., 74, 493-510, 2002.

Cox, R. A., Bloss, W. J., Jones, R. L., and Rowley, D. M.: OIO and the atmospheric cycle of iodine, Geophys. Res. Lett., 26, 18571860, 1999.

Daehlie, G. and Kjekshus, A.: Iodine oxides, Part I, Acta Chem. Scand., 18, 144-156, 1964.

Davis, D. J., Crawford, J., Liu, S., McKeen, S., Bandy, A., Thorton, D., Rowland, F., and Blake, D.: Potential impact of iodine on tropospheric levels of Ozone and other critical oxidants, J. Geophys. Res.-Atmos, 101, 2135-2147, 1996.

Duce, R. A., Wasson, J. T., Winchester, J. W., and Burns, F.: Atmo- spheric iodine, bromine, and chlorine, J. Geophys. Res.-Atmos, 68, 3943-3947, 1963.

Fuchs, N. A.: The mechanisms of aerosols, Pergamon Press, New York, 1964.

Garland, J. A. and Curtis, H.: Emission of iodine from the sea surface in the presence of Ozone, J. Geophys. Res.-Atmos, 86, 3183-3186, 1981.

Gravestock, T., Blitz, M. A., and Heard, D. E.: Kinetics study of the reaction of iodine monoxide radicals with dimethyl sulfide, Phys. Chem. Chem. Phys., 7, 2173-2181, 2005.

Himmelmann, S., Orphal, J., Bovensmann, H., Richter, A., Ladstätter-Weißenmayer, A., and Burrows, J. P.: First observation of the OIO molecule by time-resolved flash photolysis absorption spectroscopy, Chem. Phys. Lett., 251, 330-334, 1996.

Hoffmann, T., O'Dowd, C. D., and Seinfeld, J. H.: Iodine oxide homogeneous nucleation: An explanation for coastal new particle production, Geophys. Res. Lett., 28, 1949-1952, 2001.

Holleman, A. F. and Wiberg, E.: Inorganic chemistry, in: Academic Press, edited by: Wiberg, N., Berlin, 2001.

Houghton, J.: The physics of atmospheres, Cambridge University Press, Cambridge, 2002.

Jacobson, M. Z.: Fundamentals of atmospheric modelling, Cambridge University Press, Cambridge, 1999.

Jenkin, M. E., Cox, R. A., and Candeland, D. E.: Photochemical aspects of tropospheric iodine behavior, J. Atmos. Chem., 2, 359$375,1985$.

Jimenez, J. L., Bahreini, R., Cocker, D. R., Zhuang, H., Varutbangkul, V., Seinfeld, R. C., O’Dowd, C. D., and Hoffmann, T.: New particle formation from photooxidation of diiodomethane $\left(\mathrm{CH}_{2} \mathrm{I}_{2}\right)$, J. Geophys. Res.-Atmos, 108, 4318, doi:4310.1029/2002JD002 452, 2003.

Kupper, F. C., Schweigert, N., Gall, E. A., Legendre, J. M., Vilter, H., and Kloareg, B.: Iodine uptake in Laminariales involves extracellular, haloperoxidase-mediated oxidation of iodide, Planta, 207, 163-171, 1998.

Makela, J. M., Hoffmann, T., Holzke, C., Vakeva, M., Suni, T., Mattila, T., Aalto, P. P., Tapper, U., Kauppinen, E. I., and O’Dowd, C. D.: Biogenic iodine emissions and identification of endproducts in coastal ultrafine particles during nucleation bursts, J. Geophys. Res.-Atmos, 107, 8110, doi:10.1029/2001JD000580, 2002.

McFiggans, G.: Marine aerosols and iodine emissions, Nature, 433, p. 7026, 2005.

McFiggans, G., Plane, J. M. C., Allan, B. J., Carpenter, L. J., Coe, H., and O'Dowd, C.: A modeling study of iodine chemistry in the marine boundary layer, J. Geophys. Res.-Atmos, 105, 14371 14385, 2000.

McFiggans, G., Cox, R. A., Mössinger, J. C., Allan, B. J., and Plane, J. M. C.: Active chlorine release from marine aerosols: Roles for reactive iodine and nitrogen species, J. Geophys. Res.-Atmos, 107, 4271, doi:10.1029/2001JD000383, 2002.

McFiggans, G., Coe, H., Burgess, R., Allan, J., Cubison, M., Alfarra, M. R., Saunders, R., Saiz-Lopez, A., Plane, J. M. C., Wevill, D. J., Carpenter, L. J., Rickard, A. R., and Monks, P. S.: Direct evidence for coastal iodine particles from Laminaria macroalgae - linkage to emissions of molecular iodine, Atmos. Chem. Phys., 4, 701-713, 2004.

Misra, A. and Marshall, P.: Computational investigations of iodine oxides, J. Phys. Chem. A, 102, 9056-9060, 1998. 
Norton, E. G., Vaugham, G., Methven, J., Coe, H., Brooks, B., Gallagher, M., and Longley, I.: Boundary layer structure and decoupling from synoptic scale flow during NAMBLEX, Atmos. Chem. Phys., 5, 3191-3223, 2005.

O'Dowd, C. D.: On the spatial extent and evolution of coastal aerosol plumes, J. Geophys. Res.-Atmos, 107, 8105, doi:8110.1029/2001JD000 422, 2002.

O'Dowd, C. D., Lowe, J. A., Smith, M. H., Davison, B., Hewitt, N., and Harrison, R. M.: Biogenic sulphur emissions and inferred non-sea-salt-sulphate cloud condensation nuclei in and around Antarctica, J. Geophys. Res.-Atmos, 102, 12 839-12 854, 1997.

O’Dowd, C. D., Jimenez, J. L., Bahreini, R., Flagan, R. C., Seinfeld, J. H., Hameri, K., Pirjola, L., Kulmala, M., Jennings, S. G., and Hoffmann, T.: Marine aerosol formation from biogenic iodine emissions, Nature, 417, 632-636, 2002a.

O’Dowd, C. D., Hameri, K., Makela, J. M., Pirjola, L., Kulmala, M., Jennings, S. G., Berresheim, H., Hansson, H. C., de Leeuw, G., Kunz, G. J., Allen, A. G., Hewitt, C. N., Jackson, A., Viisanen, Y., and Hoffmann, T.: A dedicated study of New Particle Formation and Fate in the Coastal Environment PARFORCE: Overview of objectives and achievements, J. Geophys. Res.Atmos, 107, 8108, doi:8110.1029/2001JD000 555, 2002b.

O’Dowd, C. D., Hameri, K., Makela, J. M., Vakeva, M., Aalto, P. P., de Leeuw, G., Kunz, G. J., Becker, E., Hansson, H. C., Allen, A. G., Harrison, R. M., Berresheim, H., Geever, M., Jennings, S. G., and Kulmala, M.: Coastal new particle formation: Environmental conditions and aerosol physicochemical characteristics during nucleation bursts, J. Geophys. Res.-Atmos, 107, 8107, doi:8110.1029/2001JD000 206, 2002c.

Plane, J. M. C. and Nien, C.-F.: A study of night-time $\mathrm{NO}_{3}$ chemistry by differential optical absorption spectroscopy in measurement of atmospheric gases, in Proc. SPIE, Int. Soc. Opt. Eng., pp. 8-20, 1991 .

Plane, J. M. C. and Saiz-Lopez, A.: UV-visible Differential Optical Absorption Spectroscopy (DOAS), in: Analytical Techniques for Atmospheric Measurement, edited by: Heard, D. E., Blackwell Publishing, Oxford, in press, 2006.
Press, W. H., Flannery, B. P., A.Teukolsky, S., and Vetterling, W. T.: Numerical recipes: The art of scientific computing, Cambridge University Press, Cambridge, 1986.

Saiz-Lopez, A. and Plane, J. M. C.: Novel iodine chemistry in the marine boundary layer, Geophys. Res. Lett., 31, L04112, doi:04110.01029/02003GL019215, 2004.

Saiz-Lopez, A., Saunders, R. W., Joseph, M., and Plane, J. M. C.: Absolute absorption cross-section and photolysis rate of $\mathrm{I}_{2}$, Atmos. Chem. Phys., 4, 1443-1450, 2004.

Sander, S. P., Friedl, R. R., Golden, D. M., Kurylo, M. J., Huie, R. E., Orkin, V. L., Moortgat, G. K., Ravishankara, A. R., Kolb, C. E., Molina, M., and Finlayson-Pitts, B. J.: Chemical kinetics and photochemical data for use in stratospheric modeling: Evaluation 14, Tech. rep., Jet Propulsion Laboratory, Pasadena, California, USA, http://jpldataeval.jpl.nasa.gov/, 2003.

Saunders, R. W. and Plane, J. M. C.: Formation pathways and composition of iodine ultra-fine particles, Environ. Chem., 2, 299 303, 2005.

Stull, R. B.: An introduction to boundary layer meteorology, Kluwer Academic Publishers, London, 1988.

Truesdale, V. W., Luther, G. W., and Canosa-Mas, C.: Molecular iodine reduction in seawater - an improved rate equation considering organic compounds, Mar. Chem., 48, 1994.

Vogt, R., Sander, R., von Glasow, R., and Crutzen, P. J.: Iodine chemistry and its role in halogen activation and ozone loss in the marine boundary layer: A model study, J. Atmos. Chem., 32, 375-395, 1999.

Winklmayr, W., Reischl, G. P., Lindner, A. O., and Berner, A.: A new electromobility spectrometer for the measurement of aerosol size distributions in the size range from 1 to $1000 \mathrm{~nm}$, J. Aero. Sci., 22, 289-296, 1991.

Yoon, Y. J., O’Dowd, C. D., Sellegri, K., Pirjola, L., Chen, H., and Hoffmann, T.: Biogenic aerosol and gas flux study in and around Mace Head, in: Nucleation and Atmospheric Aerosols, edited by: Kasahara, M. and Kulmala, M., Kyoto, Japan, 2004. 